\title{
COVID-19: THE TWO SIDES OF HEALTHCARE SUPPLY CHAIN MANAGEMENT
}

\author{
Gilles Paché, Aix-Marseille University, Aix-en-Provence, France
}

\author{
dx.doi.org/10.18374/EJM-20-1.7
}

\begin{abstract}
The 2020 coronavirus crisis has highlighted main challenges in healthcare supply chain management. The European example shows that while logistics was sometimes deficient (stock management of face masks), it also played an active role in reducing the impact of the COVID-19 pandemic in terms of mortality (patient transfers between hospitals). This research note indicates that it is important to draw lessons from the coronavirus crisis that may be useful in the context of future pandemics. While logistical solutions were sometimes improvised (or emergent) in March and April 2020, the experience should lead to action plans and deliberate strategies to avoid emergency decisions in the future.
\end{abstract}

Keywords: Coronavirus crisis, Healthcare management, Logistics, Supply chain management. 